\title{
Comparing the impact of presence patterns on energy demand in residential buildings using measured data and simulation models
}

Author names: Elena Cuerda*, Olivia Guerra-Santin **, J.J. Sendra ***, Fco.Javier Neila González*

*Universidad Politécnica de Madrid, España

** Eindhoven University of Technology, Department of the Built Environment

*** Instituto Universitario de Arquitectura y Ciencias de la Construcción, Escuela

Técnica Superior de Arquitectura, Universidad de Sevilla

E-mail address of correspondence: e.cuerda@upm.es

\section{Acknowledgement}

This research has been funded by Universidad Politécnica de Madrid and partially by INTERREC IVB and the Building Technology Accelerator (BTA) - Climate Kic.

We would also like to show our gratitude to TEP 130 research group with special thanks to Jessica Fernandez-Agüera for assistance with the Blower Door test.

\section{$\underline{\text { ABSTRACT }}$}

Prediction of the energy performance of buildings helps designers with decision-making during the design process in new construction, as well as in renovation projects. Simulation software is used as a prediction tool to calculate the energy performance of buildings. However, numerous studies question its reliability due to the existing discrepancy (gap) between calculated and actual energy performance. 
Although occupant behaviour is identified as a factor of major impact on the energy performance of buildings, the complex stochastic nature of user behaviour makes it difficult to define actual occupancy patterns. As a result, standard and normative data are usually used as input in energy simulation models.

The aim of this research is to test the effect of the use of actual presence profiles on energy demand simulations compared to the use of international normative presence profiles. A study on energy demand has therefore been developed, using dynamic simulation and monitoring campaigns. The results show that the heating and cooling energy demand may differ by up to $15 \%$ depending on whether actual or standard presence profiles are used. Therefore, presence profiles should be considered as a significant factor in the adjustment of input data in renovation projects.

The final aim of this investigation is to determine the effect of using more accurate building and occupancy simulation parameters when assessing the feasibility of building renovation (payback period calculation for example). This paper focuses on the effect of presence profiles.

Keywords: Building energy performance, Occupant patterns, Occupant schedules, Occupant behaviour, Occupancy monitoring, Post-occupancy evaluation

\section{Introduction}

At present, improving energy efficiency in buildings is one of the key objectives pursued by European policymakers. To achieve this objective, dynamic thermal simulation programs are used as predictive calculation methods to determine the energy performance of buildings during design phases. These calculations are often used to 
determine the feasibility of building renovation (for example, payback periods) or the capacity to attain a design goal, sometimes in relation to building regulations (for example, energy neutrality or energy performance coefficients). Consequently, numerous studies (Branco et al., 2004; De Wilde, 2014; Jones et al., 2015; Menezes et al., 2012) have shown a gap between calculated and actual energy performance of buildings. Thus, the highly predictive potential of these tools in the design process is reduced, generating a lack of certainty on the final calculated energy efficiency.

The International Energy Agency defines the factors that have the greatest influence on the energy consumption of buildings in Annex 53 (IEA, 2016), and these are described as follows: (1) climate, (2) building envelope, (3) building energy and services systems, (4) indoor design criteria, (5) building operation and maintenance, and (6) occupant behaviour. However, despite the major advances in the study and prediction of the first five factors, the study of occupant behaviour continues to be a topic for research, as its analysis is much more complex due to its stochastic nature.

\subsection{Occupant behaviour}

Numerous studies show that energy efficiency is not merely a technological problem, as it is influenced by occupant behaviour. In fact, the human factor has a major impact in studies concerning the gap between predicted and actual energy performance of buildings. For example, the impact of occupant behaviour on retrofitting processes should be considered since investment payback periods can be seriously affected. According to Santangelo \& Tondelli (Santangelo \& Tondelli, 2017), "the more the uncertainties related to the impact of the human factor are addressed, the more the payback time of the retrofitting interventions may be reduced, increasing the attractiveness of such investments". 
It should be noted that according to data from 2013 ((INE), 2013) and 2015 ((INE), 2015), Spanish households have changed in recent years. In 2013, $24.2 \%$ of households consisted of single people, and in 2015 this figure increased to $25 \%$. Of this $25 \%$ in 2015, 40.6\% were aged 65 or over, and of these $72.9 \%$ were women. These assumptions do not allow us to suitably predict the energy performance of buildings at the design stage in renovation projects.

The energy consumption for heating in dwellings of the same characteristics can differ by up to three times due to user influence (Gram-Hanssen, 2010). This confirms that a better understanding of user attitudes is required and as a result, "more sophisticated evaluation strategies that interrelate human factors directly with the physical performance of housing also need to be developed" (Stevenson \& Leaman, 2010).

Other research, however, suggests that there are many different situations that may occur in the domestic environment, and the information available about occupants is therefore scarce (Kim, 2016). This has prompted the introduction of a new term, "Life Style Factor", which aims to include the range of parameters related to users of residential buildings, such as family composition and user lifestyle. She also considers the term "occupant behaviour model" to be a misnomer, given that energy simulation models are not capable of representing highly complex human behaviour in buildings. In its place Kim suggests the term "occupancy model" as an alternative which truly represents "a reductionist version of true occupant behaviour models"

One of the key factors for developing energy-saving policies for residential buildings, and specifically for different household styles, is the understanding of user profiles (Guerra-Santin, 2011). Likewise, technological advances should take occupant characteristics into account: social, cultural, economic, and energy-conscious attitudes. 
"Energy-conscious households save more energy with systems that require active involvement, while less energy-conscious households save more energy that do not require active involvement" (Santangelo \& Tondelli, 2017). Sun \& Hong (Sun \& Hong, 2017) quantified the impact of occupant behaviour considering three occupant behaviour styles (austerity, normal, wasteful) in terms of energy consciousness. They conclude that occupant behaviour style has significant influence on the energy used in heating systems in buildings as "buildings occupied by energy spenders could consume more than twice the energy of the energy savers".

\subsection{Modelling occupant behaviour in buildings}

Building modelling is the tool that designers normally use to predict the energy performance of buildings. However, despite its widespread use in the building design process, it is still under development in the retrofit processes of existing buildings (Hong et al., 2018).

In the case of the study of occupant behaviour, it is crucial to use fit-for-purpose modelling (Gaetani et al., 2016), selecting the most appropriate model for each case study analysed.

Simulation software such as Design Builder uses predefined occupancy profiles which respond to a conventional family made up of four active people who are not at home during the central hours of the day, a pattern which does not always correspond to the reality studied. As Motuziene et al. (Motuziene \& Vilutiene, 2013) point out, the results of the simulations show that the behaviour, age and number of occupants are variables to be taken into consideration when performing energy simulations. In addition, the use of real occupation profiles shows major differences compared to predefined ones. 
Therefore, the choice of input data related to occupancy profiles can affect the energy consumption calculations of the building. To avoid these errors, it is advisable to collect as much information as possible about the occupation of the house and preferences in order to develop more accurate profiles, based on the occupancy patterns of real building users (D’Oca \& Hong, 2015). Carpino et al. (Carpino et al., 2018) have created and distributed a questionnaire among 80 families collecting occupancy data. An average trend of occupancy profile has been developed in order to facilitate working on energy simulation.

Ouf et al. (Ouf et al., 2018) propose recommendations on how to improve building performance simulation (BPS) tools, specifically occupant-related parameters. For example, they suggest increasing direct input in BPS tools related to occupant-related parameters to simplify the data collection process for building practitioners. They also highlight the need to update standards and building energy codes which currently employ a simplistic approach, which provides schedules that do not match those of the real users. In contrast, Dong et al. (Dong et al., 2018) propose that occupancy databases be shared by researchers in view of the difficulty of collecting real data on occupancy behaviour. Mora et al. (Mora et al., 2017) suggest modelling 3 occupancy profiles (Regulation, Current-use, Statistical) to evaluate variations in energy building performance. This investigation concludes that the Regulation scenario underestimates heating energy consumption in comparison with the Current scenario, while for the Statistical family, the heating consumption increases by $19 \%$.

Guerra-Santin et al. (Guerra-Santin et al., 2018) propose an approach for renovation projects in the Netherlands in which monitored occupants' data are used to determine occupancy patterns to be used as input in simulations for calculating energy demand for 
the sizing of PV panels in energy neutral projects. In the 2ndSkin case study, they reported a three-fold difference in heating demand between single seniors and single adults; and a two-fold difference between nuclear families and single-parent households, and between senior couples and adult couples.

Zhang et al. (Zhang et al., 2018) identified gaps in existing research regarding the role of occupant behaviour in building energy performance: "the need for understanding occupants' behaviour in a systematic framework; for stronger empirical evidence beyond individual buildings and at a larger city scale; for linking occupant behaviour to socio-economic and policy variables; and for evaluating the role of occupant behaviour in the effectiveness of building energy efficiency policy".

Research by Carpino et al. (Carpino et al., 2017) analyses the influence of behavioural variables and occupancy patterns in Nearly Zero Energy Buildings. They propose two different occupancy scenarios, with different family compositions (a four-member family and a two-member family) and simulate three different occupant behaviours (saver, medium and waster). They confirm the correct use of the "Nearly" Zero term because this depends not only on the construction of the building, but also on the consumption of lighting and appliances, which are also greatly influenced by user behaviour.

The objective of this research is to analyse the influence of users' occupancy patterns (obtained from real users and international normative occupancy profiles) on the calculation of energy demand in residential buildings. This research focuses on the influence of occupants' presence on the internal heat gains of buildings but not on the use of the systems (e.g. the use of artificial lighting or HVAC systems). The effect of 
occupants' control and interaction with the building systems is considered in a further phase of this research but lies outside the scope of this paper.

The normative and standard profiles studied are the Spanish Technical Building Code (CTE, 2016), ASHRAE 90.1 (Prototype Building Modelling Specifications) (ASHRAE_90.1, 2013), ISO/TR17772-1 (Energy performance of buildings — Indoor environmental quality) (ISO/TR17772-1:, 2017), and Th-BCE (French calculation method for energy performance) (Th-BCE., 2012).

This article aims to demonstrate that the fixed presence profiles, commonly used as input data for dynamic simulation software, are not always representative of user presence in buildings, and thus reduce the predictive potential of energy demand of these tools. It first develops various presence patterns from different data sources: real users (through mixed-method methodology) (Section 3) and international norms and standards (Section 4). Subsequently, the presence patterns were introduced as input data into a building simulation model (Section 5) of a representative case study from 1970s housing stock in Madrid. Finally, a comparison between standard and actual occupancy profiles were presented and a parametric analysis performed to calculate the influence of the individual presence patterns on the energy demand of the building (Section 6).

\section{Methodology}

A more in-depth presentation of the research framework used in this investigation is found in previous publications (Cuerda et al., 2018; Cuerda et al., 2015, 2016; Cuerda et al., 2014; Guerra-Santin et al., 2016) within research which aims to further explain the influence of different factors on the "performance gap", that is to say, the difference between predicted and actual energy performance of buildings. 
In this paper, the specific factor studied is occupant presence, following a four-step methodology (Figure 1). Firstly, the building characteristics and the occupant behaviour of the residents of the case study were obtained through collecting real data. Secondly, a building energy model was developed using Design Builder software to include the input data from the field study. Seven transient energy Design Builder models were then created using the seven different presence schedules (current and standard data) as input to analyse their impact on the energy demand. Thirdly, parametric analysis was carried out to determine the influence of the different presence profiles on energy demand. Finally, the results obtained were analysed and conclusions were drawn.

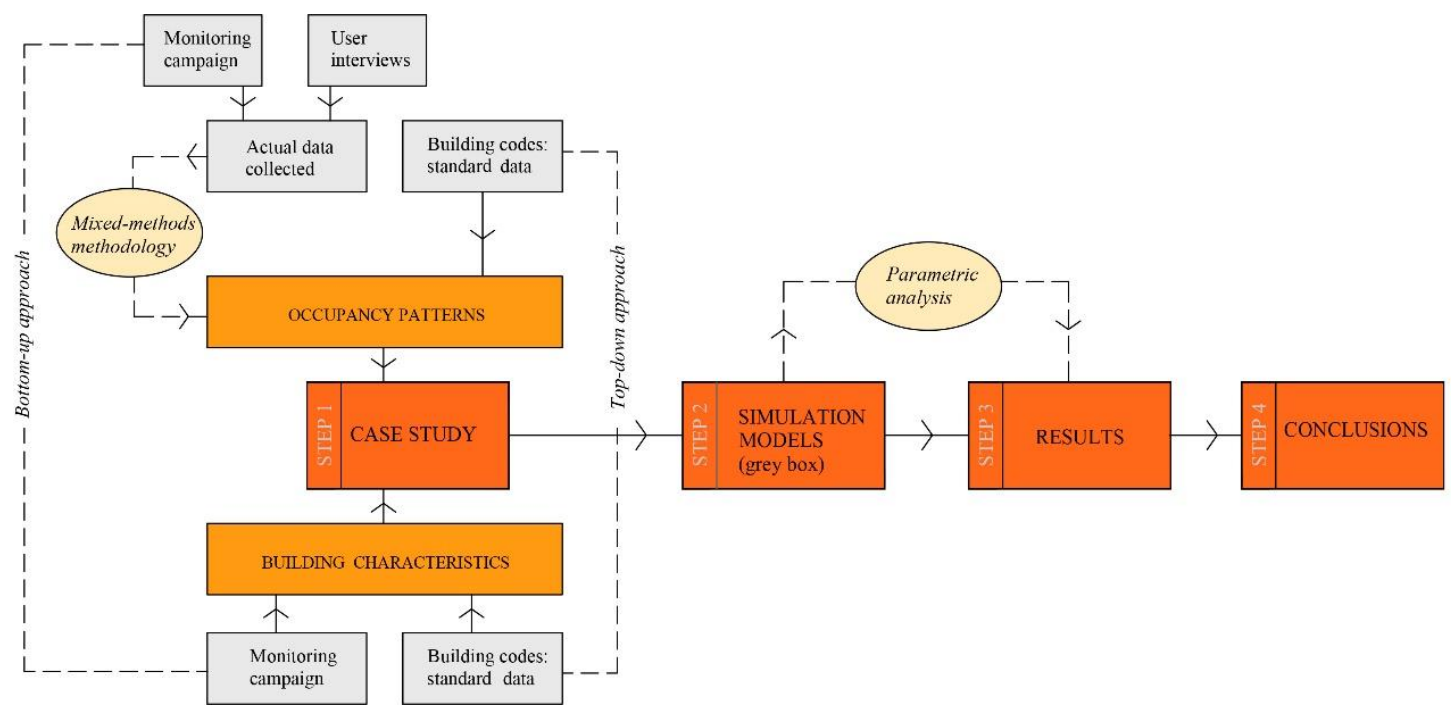

Figure 1. Methodology

To study the energy demand, a building energy base model was created incorporating input data from the field study for a real refurbished building.

Data were collected for two dwellings (CP17 and CP18) located in two originally identical buildings, although one was refurbished between 2009 and 2011. A monitoring campaign was carried out from July 2014 to July 2015 to obtain information regarding: 1) the measurement of parameters of the building envelope, 2) the electricity consumption measurement and 3) occupant behaviour data, subjective 
data on comfort and heating, cooling and ventilation-related practices of the occupants using the mixed-method approach described in O. Guerra et al. (Guerra-Santin et al., 2016).

The building envelope data were used to define the constructive parameters determining the energy performance of the building. The data on occupant behaviour and electricity consumption became the basis for defining the patterns of occupancy and habits of the users. In this study, electricity consumption was not analysed as KPI (Key Performance Indicator) to assess the energy efficiency of the building. Instead, these data were used to further specify the energy-related user practices, with the specific purpose of defining occupancy profiles that determine the presence or absence of the users at home.

\subsection{Case Studies and households}

The buildings studied are situated in an area called "Ciudad de los Angeles" in the south of Madrid (Figure 2). These buildings were built in 1972 and represent one the most common linear building typologies, based on the constructive system of the building envelope, in the period of 1950-1980 in Spain (Cuerda et al., 2014). The study was carried out in two dwellings both located in north-south oriented buildings, originally identical although one was refurbished between 2009 and 2011. Dwelling and household characteristics are defined in Table 1 and Table 2. 


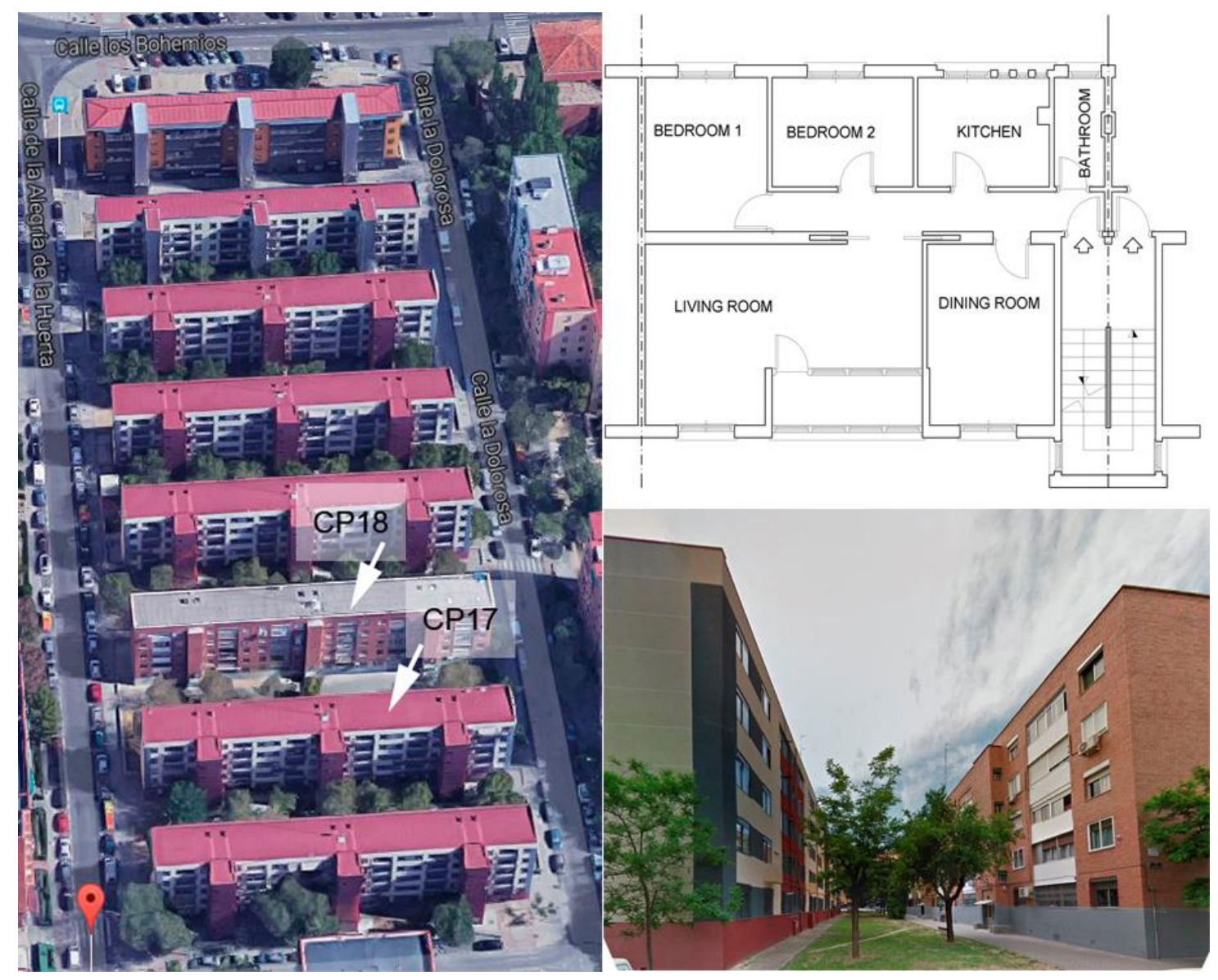

Figure 2. Case study residential buildings and case study floor plan

Table 1. Dwelling characteristics

\begin{tabular}{lcc}
\hline & Dwelling CP17 & Dwelling CP18 \\
\hline Household size & 1 & 1 \\
\hline Floor area & $62 \mathrm{~m}^{2}$ & $62 \mathrm{~m}^{2}$ \\
\hline HVAC & $\begin{array}{c}\text { Individual gas boiler } \\
\text { (Heating and water) / Air } \\
\text { conditioning }\end{array}$ & $\begin{array}{c}\text { Individual gas boiler (Heating } \\
\text { and water) / Non-air- } \\
\text { conditioning }\end{array}$ \\
\hline Tenure Type & Owner & Owner \\
\hline Dwelling type & Apartment house & Apartment house \\
\hline Construction year & 1972 & 1972 \\
\hline Last renovation & 2009/03/24-2011/03/03 & Non-renovated \\
\hline Refurbishment & Double glazing, floor & - \\
features & insulation, façade insulation & \\
\hline
\end{tabular}




\begin{tabular}{lcc}
\hline Age & Household CP17 & Household CP18 \\
\hline Gender & 83 years old & 82 years old \\
\hline Occupation & Elderly woman & Elderly woman \\
\hline Education & Employed- part time & Retired \\
\hline Physical condition & Wery good physical condition & Good physical condition \\
\hline Personality features & Dynamic and caring person. & Quiet and calm person. \\
\hline
\end{tabular}

\subsection{Building envelope data collection}

According to numerous studies (Aste et al., 2009; Goldstein \& Eley, 2014; GuerraSantin \& Tweed Aidan, 2015), the identification of faults in the building envelope is a key issue in the energy efficiency of the buildings. Therefore, the parameters selected for the purposes of monitoring were U-value of the external wall and airtightness of the building envelope.

The façade's U-value was measured with the multifunction TESTO 435-2 tool, following ISO 7726:1998 (ISO7726:1998., 2002). The north façade was measured in order to avoid direct incident radiation, with data collected in December 2015 at 10minute intervals over 24 hours. The value measured was $\mathrm{U}=0.89 \mathrm{~W} / \mathrm{m}^{2} \mathrm{~K}$.

To obtain the building airtightness, a blower door test was performed in compliance with UNE-EN 13829 (UNE-EN13829, 2000). The measured value was n50:4.08 (Air changes rate at $50 \mathrm{~Pa}$ ) and it was recorded in March 2015 for 3 hours.

The building envelope monitoring campaign is further explained in E. Cuerda et al. (Cuerda et al., 2016). The results, used as input in the building simulations, are presented in Section 6.2. 


\subsection{Post-occupancy monitoring and mixed-method approach}

A mixed-method approach (Guerra-Santin et al., 2016) was followed to define the occupancy profiles. This approach consists in the integration of different types of data collection and analysis to investigate the socio-technical aspects of occupants' behaviour in buildings in a pragmatic manner. The data collected and analysed consists of quantitative measured data from the building during the monitoring campaign from July of 2014 to July of 2015. These included building characteristics, energy consumption, indoor parameters $\left(\mathrm{CO}_{2}\right.$ level, temperature, $\mathrm{RH}$, sound, movement, and light); quantitative reported data regarding the use of heating, cooling and ventilation systems at home, as well as comfort preferences of the users; and qualitative data from interviews and walkthroughs with occupants regarding heating, cooling and ventilation practices.

Mixed methods were employed in different phases of this research. During the data collection phase, interviews and indoor parameter monitoring were carried out. The results from the monitoring were used during the interviews to obtain further insight into the lifestyle of the residents. During the data analysis phase, monitored data were triangulated with the qualitative data from the interviews to determine the occupancy profiles of each of the houses monitored.

The development of the occupancy profiles is presented in section 3 .

\subsection{Building simulation}

An energy model was developed to analyse the influence of each of the different occupancy schedules on energy demand.

A base model (Mod-AD-CP17) was created from the monitoring data collected from the CP17 case study, the refurbished building and using Design Builder software (Drury B. Crawley, 2001). Moreover, seven transient models were generated from the base model, 
with only the presence profile varying as input data. Figure 3 shows the framework on which the models are based. Firstly, the influencing factors on energy efficiency of buildings are defined. Secondly, the data compiled, and their sources, have been pointed out, and finally, the energy models generated from these data are listed.

Each model code corresponds to one occupancy profile (namely CP17 for Mod-ADCP17, CP18 for Mod-AD-CP18, SPANISH for Mod-CTE, ASHRAE for Mod-ASH, ISO-RETIRED for Mod-ISO-RET, ISO-APARTMENT for Mod-ISO-AP/DET, FRANCE for Mod-FR-Th, UNOCCUPIED for Mod-UNOCCUPIED).

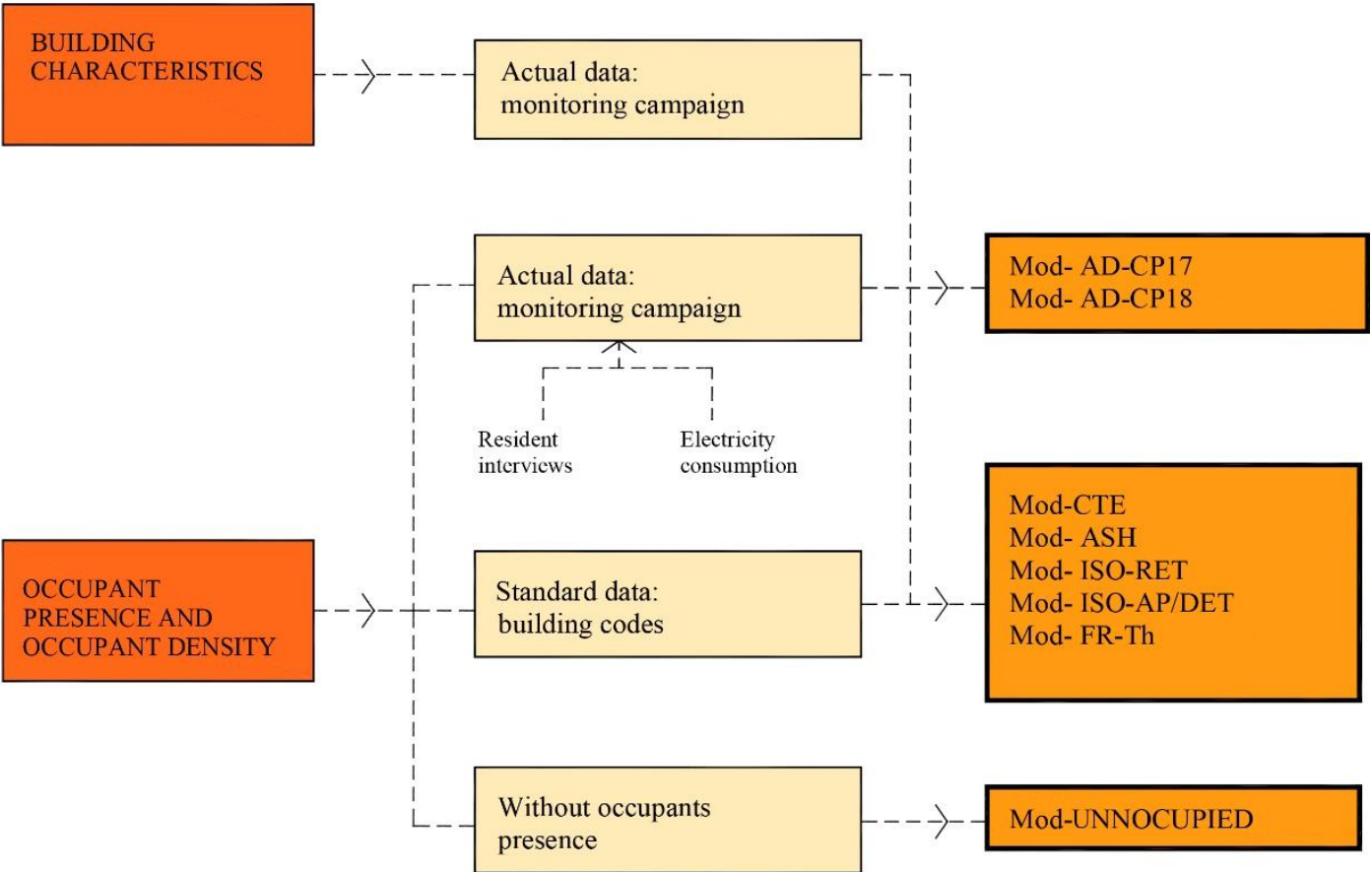

Figure 3. Building model generation 


\section{Developing actual occupancy patterns with a mixed-method approach}

In this research, we have used a pragmatic approach (mixed-methods) (O. GuerraSantin et al., 2016) to define deterministic presence profiles (CP17, CP18) using data from the monitoring campaign.

The mixed-method approach incorporates, on the one hand, qualitative data regarding occupant attitude collected from interviews with the users. On the other hand, quantitative data was obtained from the analysis of the electricity consumption, measured in the apartments.

Electricity consumption was measured for a few individual appliances and electronic devices (i.e. television, refrigerator, vitroceramic hob), as well as the total electricity consumption in the apartment. An energy wireless monitor was used to meter electricity and data on electricity consumption. The measurements were taken at 10-minute intervals for one year and the electricity consumption was used to ascertain whether the residents were home or not.

The occupancy profiles are the result of the triangulation of the electricity consumption data with the interviews carried out with the residents. The profiles were defined as follows:

1. The total electricity consumption in the apartment was used in order to develop the occupancy profiles.

2. Weekdays and weekend days were studied separately, since previous research had shown significant differences between the occupant schedules (Barbosa, 2016; Cuerda et al., 2018; Guerra-Santin et al., 2017).

3. The time intervals (hours), in which total energy consumption was measured, were coded with values between 0 (absent) and 1.0 (present). The occupancy index is the 
probability that there is occupancy in the house, and it was obtained as the average presence per hour for the year. Thus, if a value of 0.5 is observed at 12:00 pm on Wednesdays, it means that the user was at home on 12:00 pm on half of the Wednesdays of the measured year. The results plotted can be seen in Figure 4 for weekdays and Figure 5 for weekends.

4. After 21:00 hours (on weekdays) and after 22:00 hours (on weekend days), and until 7:00 hours, the electricity consumption decreases dramatically (see figures), suggesting that the residents have gone to sleep. For these time intervals, it was assumed that the occupants were at home but not using electricity and it was coded as 1.0.

5. Electricity consumption increases after 7:00 hours (on weekdays) and after 8:00 hours (on weekend days), indicating that the residents start with their daily routines.

6. Between 9:00 and 22:00 values range from 0 and 1.0 depending on the probability of occupancy in the house.

7. The mixed-method approach was used to analyse the plots. The information collected from interviews and walkthroughs with residents was used to further develop the occupancy profiles (see Figure 4 and Figure 5), for instance, corroborating the selfreporting schedules of the residents (cooking times, leaving home, etc.).

8. Week profiles were created based on the triangulated information from the analysis.

The result of the triangulation between qualitative and quantitative information can be seen in Figure 4 and Figure 5. The development of occupancy profiles is further explained in E. Cuerda et al. (Cuerda et al., 2018), while a similar method can be found in Barbosa et al. (Barbosa, 2016). 


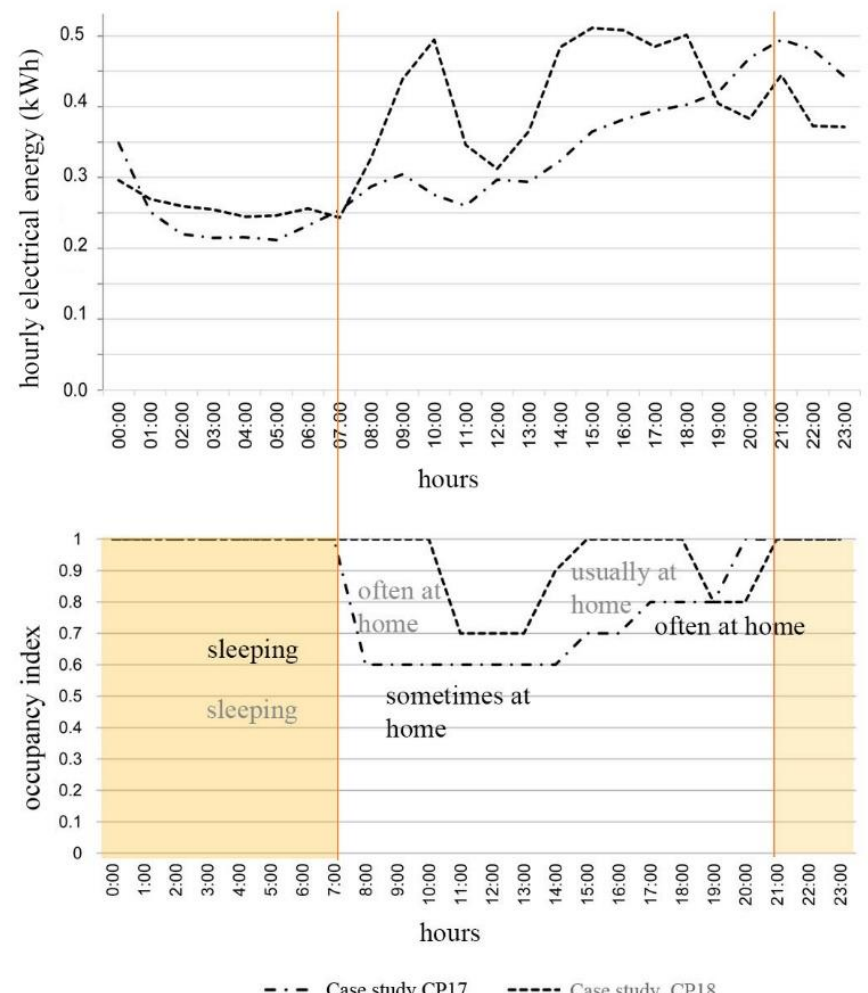

Figure 4. Weekday hourly electrical energy (above). Weekday presence profile (below).

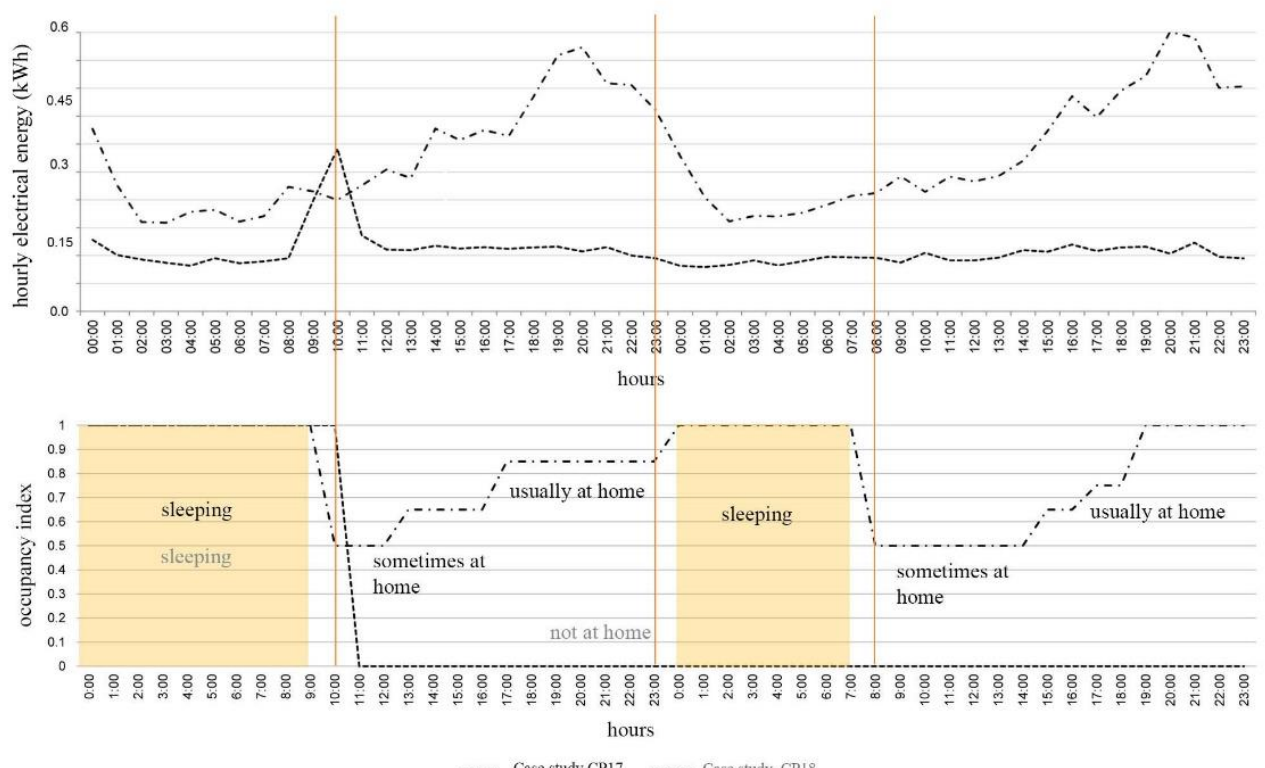

Figure 5. Weekend hourly electrical energy (above). Weekend occupant profile (below). 


\section{Standard and normative occupant profiles}

After developing actual occupant profiles for the case studies, occupancy schedules were studied from standards or energy codes, which are based upon generalised assumptions that do not match the real users.

The standards and regulations selected come from the Spanish Building Code (Spain)

(CTE, 2016), the Méthode de la réglementation thermique (France) (Th-BCE., 2012),

ASHRAE (American Society of Heating, Refrigerating and Air-Conditioning

Engineers) (ASHRAE_90.1, 2013) and ISO (International Organization for

Standardization) (ISO/TR17772-1:, 2017).

Plots are represented according to the following premises:

- The schedules are drawn up based on a daily profile, distinguishing between weekend and weekdays, and are composed of hourly values that correspond to a fraction of the occupancy peak load.

- The occupancy index is represented in the vertical axis from 0 to 1.0 (0 was assigned when it was assumed that the occupants were not at home, and a 1 when homes have full occupancy). 


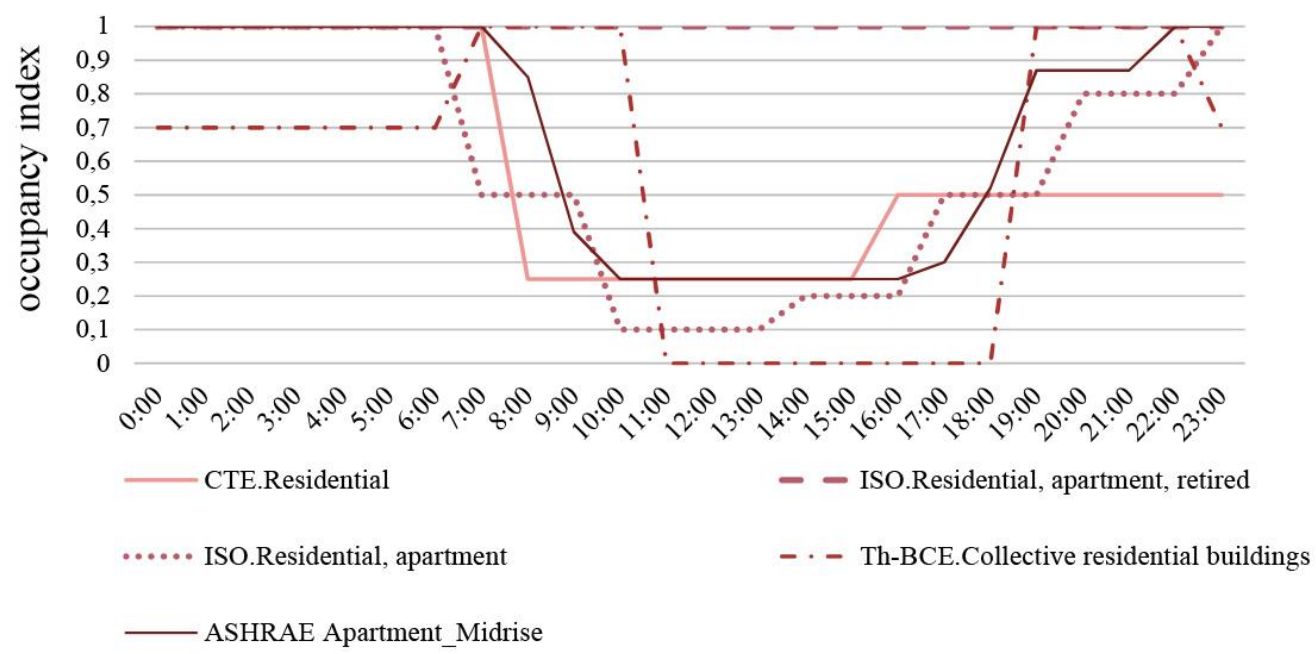

Figure 6. Occupancy profile for energy calculations. Weekdays

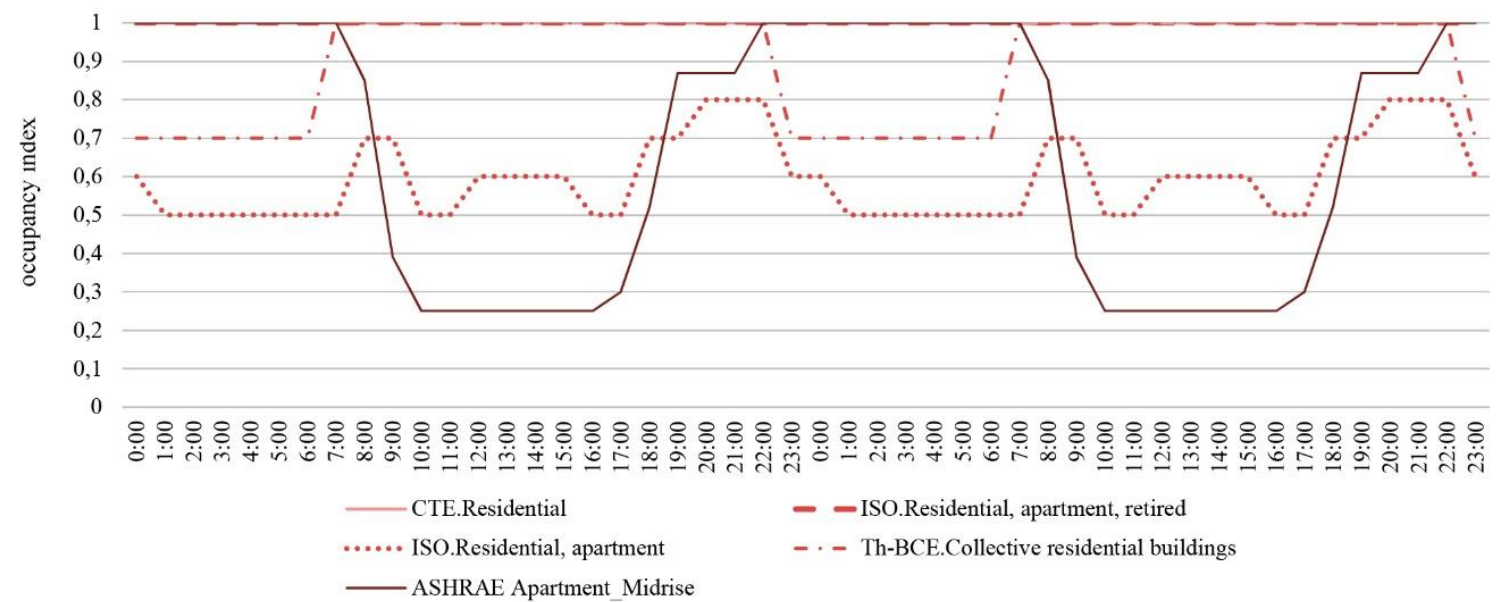

Figure 7. Occupancy profile for energy calculations. Weekend days

According to Figure 6 and Figure 7:

Spanish household members are absent from 8:00 to 15:00 hours, with only a few members back in the dwelling during the afternoon, and everybody back at home at night. 
In France, household members are absent from 11:00 to 18:00 hours, with everybody back at home during the afternoon and the night. In this case, residential buildings are fully occupied at the weekends.

The members of the household schedule provided by ASHRAE are usually away from home between 9:00-17:00. This profile of residential buildings shows no differences between weekdays and weekends.

ISO/TR 17772-1:2017 included two different occupant schedules: a specific profile for retired households and another corresponding to residential buildings, including both apartment and detached houses. The profile for retired people considers these dwellings to be fully occupied throughout the day, weekdays and weekend days included. However, in the residential building profile, members gradually leave home from 7:00 to 9:00 hours, and gradually return home from 14:00 to 19:00. During the night, everybody is back at home. For weekend days, the profile is more regular, and apartments and detached houses have a very high occupancy rate between 7:00 and 22:00 hours.

Other building codes and national normative studied were not included given the limited information regarding residential occupancy profiles. For example, in the regulations from Italy (Legge_90/13, 2015), and Portugal (Decreto-Lei_79/2006, 2006), we found data regarding occupant profiles for different building types but not for residential buildings.

HETUS (Harmonised European Time Use Survey) is a European database (Eurostat). Since the 1990s, the organisation and activities of everyday life in fifteen European countries have been collected from surveys. It provides a wide variety of statistical images of people's use of time in these countries. The information is divided into the 
following activities: work, study, domestic work, travel, sleep, having meals, use of personal car, and free time. Even though this information can be very useful when studying the time spent on each activity, in different countries and groups of people, it is not possible to develop occupancy profiles based on when residents are away or at home, as some of the tasks can be carried out both inside or outside the house (for example free time or domestic work).

\section{Energy simulation model}

This section examines the effect of using actual presence profiles on the energy demand in building simulations. Therefore, to isolate the studied parameter (i.e. presence profiles), only the refurbished building of the case studies (CP17) was modelled as the base model for the study. A sensitive analysis was performed, modelling seven transient models, only varying the different occupancy patterns developed. All other variables in the building simulation are kept constant. This sensitivity analysis will allow us to ascertain the possible impact on energy demand caused by using standardised occupancy patterns on building simulations. Further studies will look at the optimization of the other building and occupancy parameters.

The information to be used as input in the model was collected from various sources:

Geometry: Building drawings and other documents were obtained from the original architectural design team. Building geometry was then generated based on this information.

Constructive building elements: In the renovated building, the original masonry façade was retrofitted with a system consisting of a 4-cm layer of expanded polystyrene (SATE system). In addition, the single layer glazing $(3 \mathrm{~mm})$ and aluminium 
frames were updated by adding an external window with aluminium frame and Climalit 4/6/4 glazing without solar treatment.

Some of the characteristics of the dwelling were monitored (Section 2.2), while others were based on the Spanish regulation and an officially recognised database (Table 3).

Table 3. Building construction parameters

\begin{tabular}{|c|c|c|c|}
\hline Input variable & \multirow[t]{2}{*}{ Element } & \multirow[b]{2}{*}{ Expected performance } & Values \\
\hline \multirow{5}{*}{ U- values } & & & $\begin{array}{c}\text { Measured } \\
\text { Performance }\end{array}$ \\
\hline & External wall & - & $0.89 \mathrm{~W} / \mathrm{m}^{2} \mathrm{~K}$ \\
\hline & Floors & $0.3 \mathrm{~W} / \mathrm{m}^{2} \mathrm{~K}$ & - \\
\hline & $\begin{array}{c}\text { Windows } \\
\text { (north-south oriented) }\end{array}$ & $\begin{array}{l}2.08 \mathrm{~W} / \mathrm{m}^{2} \mathrm{~K} \\
(\mathrm{SHGC} 0.63)\end{array}$ & - \\
\hline & Roof & $0.57 \mathrm{~W} / \mathrm{m}^{2} \mathrm{~K}$ & - \\
\hline Air tightness & & & \\
\hline $\begin{array}{l}\text { Air changes rate } \\
\text { at } 50 \mathrm{~Pa}\left(\mathrm{n}_{50}\right)\end{array}$ & Building envelope & - & $4.08 \mathrm{~h}^{-1}$ \\
\hline
\end{tabular}

Weather data: The weather data used were provided by a meteorological station located within the neighbourhood, near the case studies. Weather data were collected for two years at 10-minute intervals and used to generate a new weather file in Design Builder. The data collected were dry bulb temperature $\left({ }^{\circ} \mathrm{C}\right)$, relative humidity $(\%)$, global horizontal radiation $\left(\mathrm{Wh} / \mathrm{m}^{2}\right)$, wind direction $(\mathrm{deg})$, and wind speed $(\mathrm{m} / \mathrm{s})$.

\section{Operation parameters:}

The operation parameters selected are illustrated in Table 4. All these parameters were considered input according to current regulation and recognised Spanish databases (CTE, 2016). 
The HVAC system consists of an individual natural gas boiler and radiators (heating) and fan coil units (cooling) in all rooms. The simulation period for winter was December $1^{\text {st }}$ to February $28^{\text {th }}$ and for summer June $1^{\text {st }}$ to September $30^{\text {th }}$ (Table 4 ).

Table 4. Operation parameters

\begin{tabular}{|c|c|c|}
\hline \multirow[t]{2}{*}{ Parameter } & \multicolumn{2}{|c|}{ Values/Data } \\
\hline & \multirow[b]{2}{*}{ Winter/heating period } & \multirow[b]{2}{*}{ Summer/cooling period } \\
\hline & & \\
\hline \multirow[t]{2}{*}{ Heating and cooling period } & 1DEC-28FEB & 1JUN-30SEPT \\
\hline & Max & Min \\
\hline Tsp heating $\left({ }^{\circ} \mathrm{C}\right)$ & 20 & 17 \\
\hline Tsp cooling $\left({ }^{\circ} \mathrm{C}\right)$ & 25 & 27 \\
\hline \multicolumn{3}{|l|}{ Mechanical ventilation } \\
\hline Winter period (ach) & \multicolumn{2}{|c|}{$1.2(24 / 7)$} \\
\hline Summer period (ach) & \multicolumn{2}{|c|}{$1.2(8: 00-00: 00)-4(00: 00-8: 00)$} \\
\hline \multicolumn{3}{|l|}{ Lighting and appliances } \\
\hline Power density $\left(\mathrm{W} / \mathrm{m}^{2}\right)$ & \multicolumn{2}{|c|}{4.4} \\
\hline Schedule & \multicolumn{2}{|c|}{ Weekdays, Sat. and Sun.: 16:00-00:00 } \\
\hline
\end{tabular}

\section{Occupancy parameters:}

The occupancy schedules vary from model to model, as illustrated in Table 5.

The household composition (occupancy density) in the base model was calculated from the case study CP17 $\left(0.02 \mathrm{per} / \mathrm{m}^{2}\right)$. According to the standard and normative household composition studied (BOE), occupancy density value is $0.04 \mathrm{per} / \mathrm{m}^{2}$ (Table 5).

Table 5. Energy models and varying occupancy parameters

\begin{tabular}{|c|c|c|c|c|c|c|c|c|}
\hline & $\begin{array}{c}\text { Base } \\
\text { model }\end{array}$ & $\begin{array}{l}\text { Transient } \\
\text { model } 1\end{array}$ & $\begin{array}{l}\text { Transient } \\
\text { model } 2\end{array}$ & $\begin{array}{c}\text { Transient } \\
\text { model } 3\end{array}$ & $\begin{array}{c}\text { Transient } \\
\text { model } 4\end{array}$ & $\begin{array}{c}\text { Transient } \\
\text { model } 5\end{array}$ & $\begin{array}{l}\text { Transient } \\
\text { model } 6\end{array}$ & $\begin{array}{c}\text { Transient } \\
\text { model } 7\end{array}$ \\
\hline $\begin{array}{l}\text { Energy } \\
\text { models }\end{array}$ & $\begin{array}{l}\text { Mod-AD- } \\
\text { CP17 }\end{array}$ & $\begin{array}{l}\text { Mod-AD- } \\
\text { CP18 }\end{array}$ & $\mathrm{M}$ & $\begin{array}{l}\text { Mod- } \\
\text { ASH }\end{array}$ & $\begin{array}{l}\text { Mod-ISO- } \\
\text { RET }\end{array}$ & $\begin{array}{c}\text { Mod-ISO- } \\
\text { AP/DET }\end{array}$ & $\begin{array}{l}\text { Mod-FR- } \\
\text { Th }\end{array}$ & $\begin{array}{c}\text { Mod- } \\
\text { UNNOC }\end{array}$ \\
\hline $\begin{array}{l}\text { Occupancy } \\
\text { schedule }\end{array}$ & $\begin{array}{c}\text { CP17 } \\
(\text { See } \\
\text { Fig.4, 5) }\end{array}$ & $\begin{array}{c}\text { CP18 } \\
(\text { See } \\
\text { Fig.4, 5) }\end{array}$ & $\begin{array}{l}\text { SPANISH } \\
(\text { See } \\
\text { Fig.6, 7) }\end{array}$ & $\begin{array}{c}\text { ASHRAE } \\
(\text { See } \\
\text { Fig.6, 7) }\end{array}$ & $\begin{array}{l}\text { ISO-RET } \\
\quad(\text { See } \\
\text { Fig.6, 7) }\end{array}$ & $\begin{array}{c}\text { ISO-APAR } \\
\text { (See Fig.6, } \\
7)\end{array}$ & $\begin{array}{l}\text { FRANCE } \\
\quad(\text { See } \\
\text { Fig.6, 7) }\end{array}$ & $\begin{array}{c}\text { UNNOC } \\
\text { (occupanc } \\
\text { y off) }\end{array}$ \\
\hline
\end{tabular}


Occupancy

density

0.02

0.02

0.04

0.04

0.04

0.04

0.04

0.04

(people/m2)

The occupancy parameters relating to internal gains due to people are illustrated in

Table 6.

Table 6. Occupancy parameters

\begin{tabular}{lc}
\hline Parameter & Value/Activity \\
\hline Schedule and occupancy density & See Table 5 \\
\hline Occupancy gains (W/per) & 117.2 \\
\hline Winter clothing (CLO) & 1 \\
\hline Summer clothing (CLO) & 0.5 \\
\hline
\end{tabular}

\section{Results}

\subsection{Comparison standard vs. actual occupancy profiles}

In this section, the standard or normative profiles are compared with the actual occupancy profiles from the case studies. The goal is to identify the differences between the standard and the actual presence profiles and schedules.

Standard occupancy profiles usually include a household consisting of a nuclear family (four occupants). However, the occupancy profiles studied (CP17 and CP18) consist of only one occupant per home. This difference is reflected in the occupancy density in Table 5.

Table 7 shows the occupant schedules summarised.

Table 7. Occupancy schedules. Actual data and Standard and normative data. CP17, CP18, Spanish Technical Code (CTE), ASHRAE 90.1, ISO-FDIS 17772-1, French Building Regulation (Th-BCE). Weekdays and weekends. 


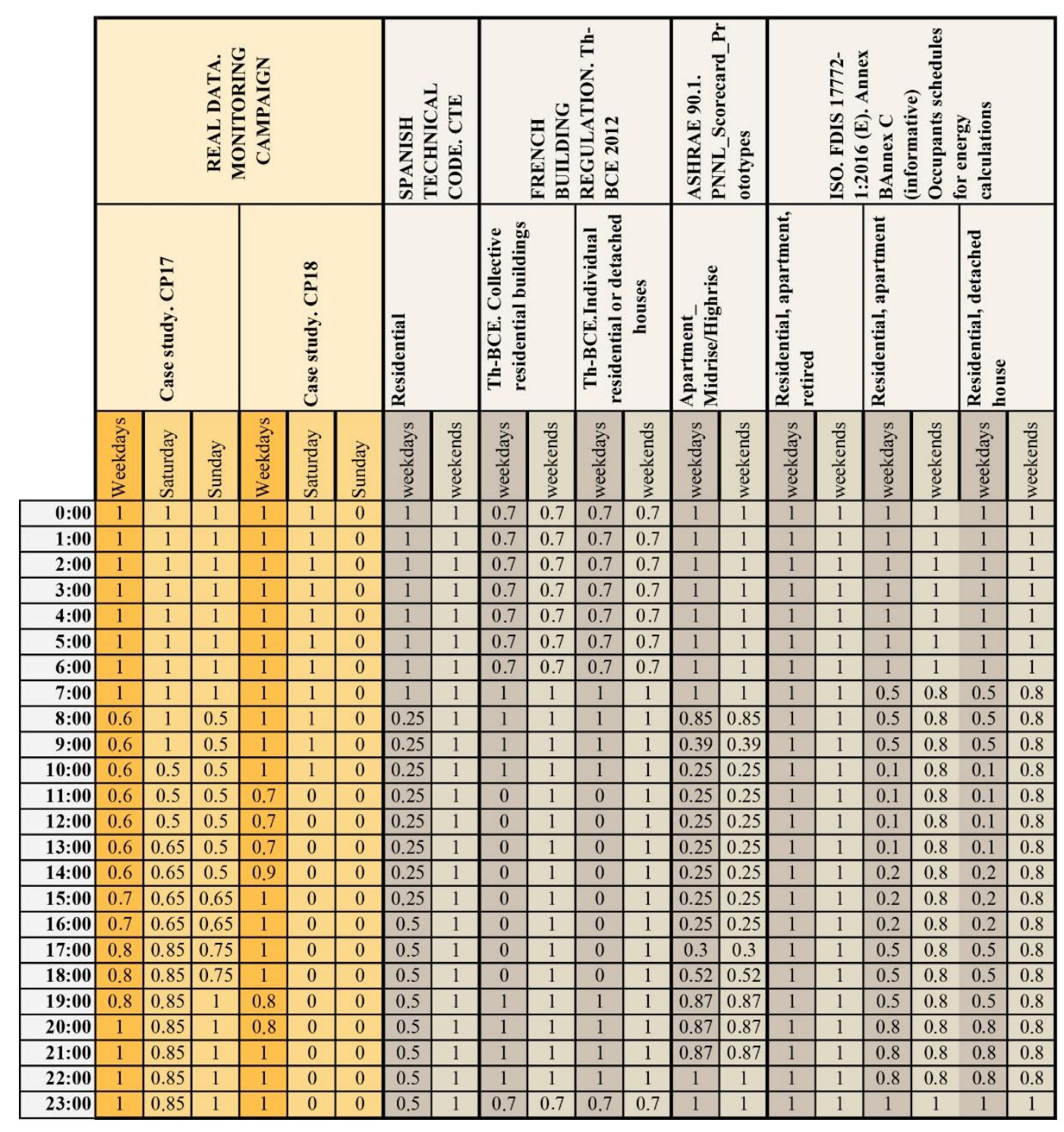

In Table 7, the first columns represent the occupancy profiles developed for the two case studies presented in section 3 resulting from the mixed-method approach.

The household characteristics of CP17 and CP18 show similarities: both consist of single elderly women with similar routines. However, occupant schedules show some differences. According to the interviews, during morning weekdays, the resident of CP17 leaves the house because she works part-time. The CP18 resident also leaves the house in the morning, but for a shorter period (10:00-12:00 hours). In CP18, cleaning and cooking between 8:00 and 10:00 increases the energy consumption (Figure 4). 
During the weekends there are significant differences between these two profiles: the resident of CP18 is usually absent during the weekends and until Monday morning, according to interviews and the electric consumption charts (Figure 4, Figure 5); while the resident of CP17 maintains a similar profile on weekdays and weekends.

Comparing the actual profiles with the standard profiles, the most important differences are highlighted below:

- It can be noted that the actual occupancy profiles (case studies) show a higher occupancy rate during the weekdays than the standard schedules. However, except for the ASHRAE schedule, the standard profiles show a higher occupancy rate during the weekend days than the case studies.

- The standard schedules have a very high occupancy rate on weekend days (between 0.8-1), except in the case of the ASHRAE schedule, which shows no difference between weekdays and weekend days.

- French building regulation proposes two schedules differentiating collective from detached/single-family buildings. However, both schedules have identical values. This regulation does not only define occupancy rates but also makes it possible to calculate various parameters relating to the energy efficiency of buildings.

- The occupancy rate at night in the Th-BCE (French regulation) is 0.7 while in the other standard schedules it is 1 . This standard is the only one that does not regard sleeping time as full occupancy $(100 \%)$, since it estimates that this value is reduced while occupants sleep due to a lower metabolic rate.

- The ISO standard proposes three schedules: apartment, detached house and apartment with retired person. The first two have identical values but this is the only regulation 
that puts forward a specific schedule for retired people. This schedule type has a full occupancy rate during the whole day for weekdays and weekend days.

\subsection{Energy demand and occupancy data analysis}

The heating energy demand was analysed for the heating period (winter), namely December, January and February. The cooling energy demand was analysed for the cooling period (summer), namely June, July, August and September. These periods were selected according to the Spanish Building Code (CTE, 2016).

Total heating demand and internal gains by occupants

Figure 8 shows the total heating energy demand (dark grey) and the internal heat gains by occupants (soft grey) calculated for each of the eight energy models listed in Section

5. The heating energy demand was analysed according to the Spanish Building Code for the heating period, namely December, January and February.

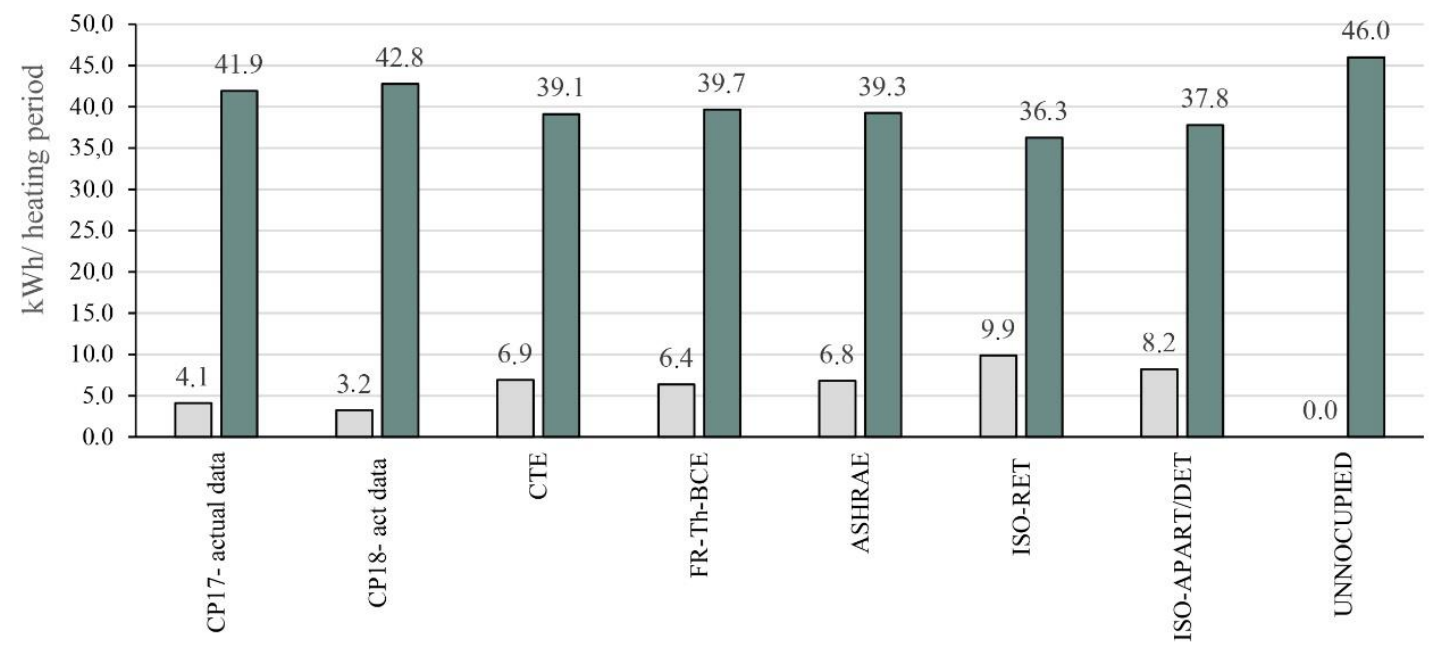

Figure 8. Total heating demand and heat gains by occupants ( $k W h)$

In Figure 8, the variation between the highest and lowest result of total heating demand when the dwelling is occupied, is $6.5 \mathrm{kWh}$. This represents a variation of $15 \%$. 
The higher the heat gains by occupants the lower the heating demand.

The heating demand between the real and standard occupancy profiles does not differ too much, the differences are between 1.8 and $6.5 \mathrm{kWh}$. In Section 6.1 it is shown that there is an important difference in the daily routines of the two case studies, which are inverted from week days to weekend days. This difference balances out the values. $\mathrm{CP} 17$ and $\mathrm{CP} 18$ profiles present similar results but the heat gains by occupants in $\mathrm{CP} 17$ are higher than in CP18. The reason for this difference is that the occupant of CP18 leaves home for the weekend during 2 complete days. This represents $28 \%$ of the whole week.

The profile of the retired people (ISO-RET) has full occupancy during the whole day (weekdays and weekend days). Thus, it produces the highest value for heat gains by occupants and thus the lowest value of total heating demand out of the other profiles studied.

The results of the total heating demand in SPAIN, FRANCE and ASHRAE are very similar, with a difference of less than $1 \mathrm{kWh}$.

\section{$\underline{\text { Total cooling demand and internal gains by occupant }}$}

In Figure 9, the variation between the highest and lowest result of total cooling demand when the dwelling is occupied is $3.4 \mathrm{kWh}$ and this represents a variation of $15 \%$ (similar to the total heating demand). 


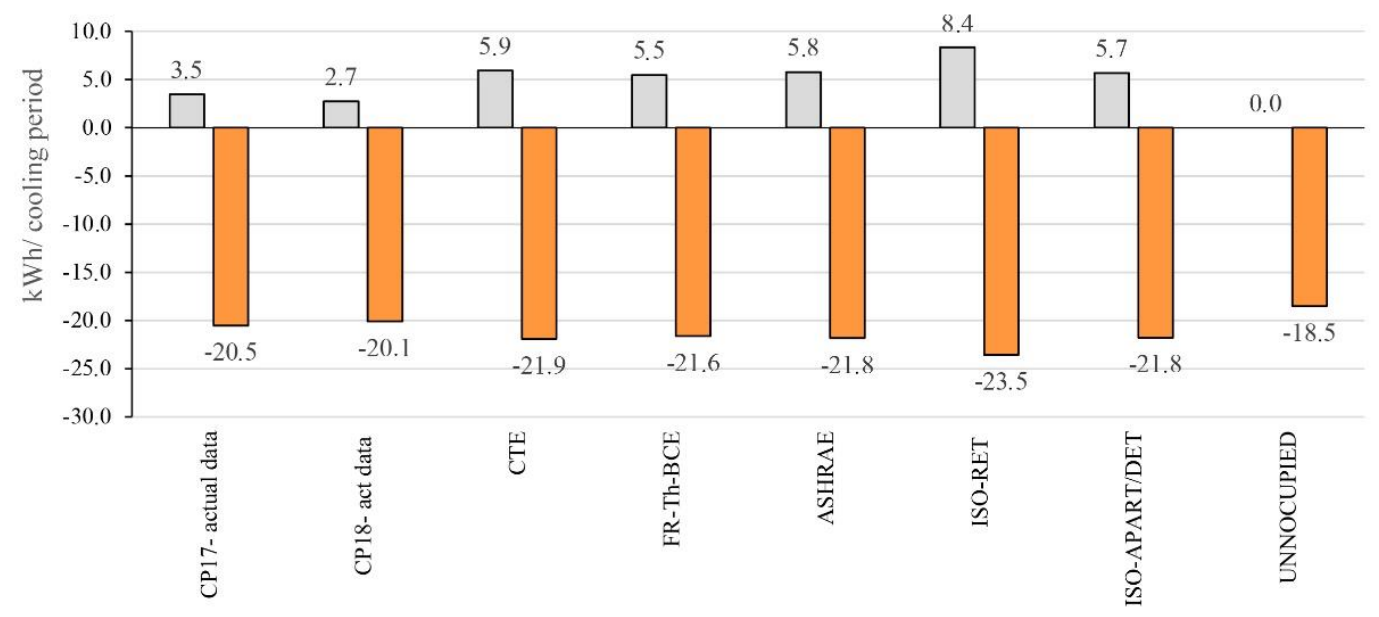

Figure 9. Total cooling demand and heat gains by occupant ( $k W h$ )

The higher the heat gains by occupant the greater the cooling demand.

The results of the total cooling demand in SPAIN, FRANCE and ASHRAE are very similar, and the difference between them is less than $0.5 \mathrm{kWh}$.

The ISO-RET profile represents the highest value in heat gains by occupant and unsurprisingly it is the highest value in cooling demand.

Since the total cooling demand values are lower than the heating ones and the heat gains by occupant are similar in winter and summer, the influence of the heat gains by occupant has a higher effect in the cooling demand.

\section{Discussion}

While thermal dynamic simulation programs are increasingly accurate in the evaluation of the physical behaviour of the building, the use of the parameters relating to occupants continues to be considered in a simplistic way, unifying behaviours and singularities in a single pattern, regardless of the different socio-economic characteristics of the occupants, climate or use of the building. These assumptions often produce errors in the predictions of the energy demand calculated with simulation programs. For this reason, 
the simulation of the actual occupancy of buildings is crucial to establish the real energy performance of buildings. Thus, a more experimental approach that allows us to obtain information about the users that inhabit the houses is necessary. In this case, since not all building conditions and occupant behaviour could be measured (monitored), there are a few uncertainties that might be important for the simulation. For example, there is no information about the status of windows, shading elements or internal doors when the resident leaves the house. Therefore, the windows have been considered to be closed and internal doors and shading elements to be completely open. A sensitivity analysis will be performed in further phases of the study.

Furthermore, in the case of energy rehabilitation projects, for example within a certain neighbourhood, local sociological and statistical studies affecting the characteristics of their population should be taken into account. Moreover, since households are constantly varying, rehabilitation projects should take into consideration the specific features of the household typologies most represented in the area. For instance, the retired profile (ISO) could be applicable to households of certain age (very old or sick people), in particular countries (where the climate does not favour elderly people getting out of the house every day), or cultural attitudes. However, for example in Spain, elderly and retired people usually get out every day, sometimes for running errands, light shopping, or simply sitting in a street seat. The residents of the case studies are two elderly women; both of retiring age. However, CP17 is still working part-time, and CP18 gets out every day for different activities. In addition, there are also differences between these two profiles, analysed in Section 6.1. Interestingly enough, these differences balance out the profiles, since the resident of CP17 spends less time at home on weekdays while CP18 is away from home on the weekends and vice versa. 
The occupancy profiles presented here are intended to demonstrate the effect of actual, monitored data in comparison to standardised data. These profiles are not meant to be used in other cases, or to be extrapolated, since they only respond to these case studies and their specific locations and users. The proposed methodology involves measuring the occupancy in actual buildings to be renovated on a case by case basis in a pragmatic way. Therefore, in practice, this type of simulation (with real data) can be used in renovation projects, but not in new buildings, where occupancy profiles based on statistical data would be advisable as they can be more generalised to a type of family. The cost of measuring devices has decreased over the last few years, while their simplicity has increased. Measuring individual households is not as prohibitive as it was before. On the one hand, it could improve building performance by allowing more accurate calculation on energy demand, and on the other hand improve the liveability of buildings, since the lifestyle and needs of the occupants can be better considered.

\section{Conclusions}

In this research, monitoring data from two case studies have been used to define more accurate occupancy profiles. The profiles developed were used as input on energy simulation models to determine the influence of internal heat gains from occupants on the dwellings' energy demand and to understand the effect of using standard profiles instead of actual profiles. In order to do so, actual profiles were compared to the profiles established by national and international standards.

With the exception of ASHRAE, which considers the weekend in the same way as a weekday, all profiles have a high occupancy rate on weekends (0.8-1.0), also higher than the case studies (CP17 and CP18). FRANCE is the only profile that considers the nocturnal metabolic rates of 0.7 . 
These differences between the standard profiles do not show significant variations in the results of the simulation since the results of heating and cooling demand using ASHRAE, FR and CTE profiles are very similar, with variations between $0.5 \mathrm{kWh}$ in cooling demand and $1 \mathrm{kWh}$ in heating demand. However, the differences between the actual and the standard profiles were larger. The results highlighted that the variation between the highest and lowest results of total heating and cooling demand using standard and actual profiles is $6.5 \mathrm{kWh}$ (heating) and $3.4 \mathrm{kWh}$ (cooling). In both cases, this represents a variation of $15 \%$.

The results highlight that the use of a specific profile for retired people can be useful because it has an important influence on cooling and heating demand, but that it should be adjusted to different climatic and socio-cultural situations.

This paper has proposed a way forward in terms of methodology for the designers using simulation programs to predict the energy performance of buildings. The results obtained show the need for a future review of the simplification and standardization of occupancy profiles commonly used by practitioners to calculate energy demand in the design phase of buildings. Specifically, incorporating socio-cultural aspects in the definition of presence profiles is needed, since the analysis shows that although the regulations of the countries investigated include different profiles according to diverse types of households; these profiles still fall short of reflecting a variety of socioeconomical parameters relating to lifestyle, heath condition or family situation.

This investigation has shown that the application of the mixed-method approach, in which the monitored data of different building variables combined with user surveys makes it possible to define actual occupancy profiles. This study has shown that the analysis of monitored data on user behaviour allows us to adjust the occupancy patterns 
to reality in the simulation programs. This allows us to evaluate the building energy performance, adjusting it more to real use. To make even more accurate simulations it would be useful to collect other types of information regarding occupant behaviour, for example, internal gains of electrical equipment, preference for internal temperature setpoint, ventilation behaviour, shading elements, etc. In the case of rehabilitation projects, it will allow the optimization of these patterns, adjusting them for the current user and their peculiarities, and furthermore it will enable a truly predictive study of the energy behaviour at the time of undertaking the rehabilitation project. This will be the subject of further research.

\section{References}

(INE), I. N. d. E. (2013). Características de los hogares. Ministerio de Economía y Competitividad.

(INE), I. N. d. E. (2015). Continuous Household Survey.

ASHRAE_90.1. (2013). ASHRAE. 90.1 Prototype Building Models Mid-rise Apartment. Retrieved 18-05-2018, from https://www.energycodes.gov/901-prototype-buildingmodels-mid-rise-apartment

Aste, N., Angelotti, A., \& Buzzetti, M. (2009). The influence of the external walls thermal inertia on the energy performance of well insulated buildings. Energy and Buildings, 41(11), 1181-1187. doi: http://dx.doi.org/10.1016/j.enbuild.2009.06.005

Barbosa, J. M., R.; Braganza, L. (2016). Occupancy Patterns and Building Performance Developing occupancy patterns for Portuguese residential buildings. Paper presented at the SBE16 Brazil \& Portugal - Sustainable Urban Communities towards a Nearly Zero Impact Built Environment, Vitoria, Brazil.

BOE, B. O. d. E.). Código de la vivienda de la Comunidad de Madrid.

Branco, G., Lachal, B., Gallinelli, P., \& Weber, W. (2004). Predicted versus observed heat consumption of a low energy multifamily complex in Switzerland based on long-term experimental data. Energy and Buildings, 36(6), 543-555. doi: http://dx.doi.org/10.1016/j.enbuild.2004.01.028

Carpino, C., Fajilla, G., Gaudio, A., Mora, D., \& De Simone, M. (2018). Application of survey on energy consumption and occupancy in residential buildings

Carpino, C., Mora, D., Arcuri, N., \& De Simone, M. (2017). Behavioral variables and occupancy patterns in the design and modeling of Nearly Zero Energy Buildings. Building Simulation, 10(6), 875-888. doi: 10.1007/s12273-017-0371-2 
CTE. (2016). CTE. Código Técnico de Edificación. DB HE Ahorro de energía. from https://www.codigotecnico.org/

Cuerda, E., Guerra-Santin, O., \& Neila González, F. J. (2018). Definiendo patrones de ocupación mediante la monitorización de edificios existentes. Informes de la Construcción, 69(548), 223. doi: 10.3989/id.53526

Cuerda, E., Guerra-Santin, O., Neila González, F. J., \& Romero Herrera, N. (2015). Postoccupancy monitoring of two flats in Madrid: development and assessment of a mixed methods methodology. Paper presented at the Passive and Low Energy Architecture (PLEA), Bologna. Italy.

Cuerda, E., Guerra-Santin, O., Neila González, F. J., \& Romero Herrera, N. (2016). Evaluation and comparison of building performande in use. Paper presented at the Third International Building Performance Simulation Associarion. England Conference, Newcastle.

Cuerda, E., Pérez, M., \& Neila, J. (2014). Facade typologies as a tool for selecting refurbishment measures for the Spanish residential building stock. Energy and Buildings. doi: http://dx.doi.org/10.1016/j.enbuild.2014.02.054

D'Oca, S., \& Hong, T. (2015). Occupancy schedules learning process through a data mining framework. Energy and Buildings, 88, 395-408. doi: 10.1016/j.enbuild.2014.11.065

De Wilde, P. (2014). The gap between predicted and measured energy performance of buildings: A framework for investigation. Automation in Construction, 41, 40-49. doi: http://dx.doi.org/10.1016/j.autcon.2014.02.009

Decreto-Lei no 79/2006, Regulamento dos Sistemas Energéticos de Climatização em EdifíciosRSECE C.F.R. (2006).

Dong, B., Yan, D., Li, Z., Jin, Y., Feng, X., \& Fontenot, H. (2018). Modeling occupancy and behavior for better building design and operation-A critical review. Building Simulation, 11(5), 899-921. doi: 10.1007/s12273-018-0452-x

Drury B. Crawley, L. K. L. (2001). Energy Plus: creating a new-generation building energy simulation program. Energy and Buildings, 33, 319-331.

Eurostat.). HETUS. Harmonised European Time Use Survey. from https://www.h6.scb.se/tus/tus/default.htm

Gaetani, I., Hoes, P.-J., \& Hensen, J. L. M. (2016). Occupant behavior in building energy simulation: Towards a fit-for-purpose modeling strategy. Energy and Buildings, 121, 188-204. doi: 10.1016/j.enbuild.2016.03.038

Goldstein, D. B., \& Eley, C. (2014). A classification of building energy performance indices. Energy Efficiency, 7(2), 353-375.

Gram-Hanssen, K. (2010). Residential heat comfort practices: understanding users. Building Research \& Information, 38(2), 175-186. doi: http://dx.doi.org/10.1080/09613210903541527

Guerra-Santin, O. (2011). Behavioural patterns and user profiles related to energy consumption for heating. Energy and Buildings, 43(10), 2662-2672.

Guerra-Santin, O., Boess, S., Konstantinou, T., Romero Herrera, N., Klein, T., \& Silvester, S. (2017). Designing for residents: Building monitoring and co-creation in social housing 
renovation in the Netherlands. Energy Research \& Social Science. doi: 10.1016/j.erss.2017.03.009

Guerra-Santin, O., Bosch, H., Budde, P., Konstantinou, T., Boess, S., Klein, T., \& Silvester, S. (2018). Considering user profiles and occupants' behaviour on a zero energy renovation strategy for multi-family housing in the Netherlands. Energy Efficiency. doi: 10.1007/s12053-018-9626-8

Guerra-Santin, O., Herrera, N. R., Cuerda, E., \& Keyson, D. (2016). Mixed methods approach to determine occupants' behaviour-Analysis of two case studies. Energy and Buildings, $130,546-566$.

Guerra-Santin, O., \& Tweed Aidan, C. (2015). In-use monitoring of buildings: an overview and classification of evaluation methods. Energy and Buildings(0). doi: http://dx.doi.org/10.1016/j.enbuild.2014.10.005

Hong, T., Langevin, J., \& Sun, K. (2018). Building simulation: Ten challenges. Building Simulation, 11(5), 871-898. doi: 10.1007/s12273-018-0444-x

IEA. (2016). EBC Annex 53. Total Energy Use in Buildings: Analysis and Evaluation Methods (summary report).

ISO 7726:1998.Ergonomics of the thermal environment - Instruments for measuring physical quantities. (ISO 7726:1998) (2002).

ISO/TR17772-1:. (2017). ISO/TR 17772-1:2017. Energy Performance Of Buildings. Retrieved 18-05-2018, from https://www.iso.org/standard/60498.html

Jones, R. V., de Wilde, P., \& Fuertes, A. (2015). The gap between simulated and measured energy performance: A case study across six identical new-build flats in the UK. Paper presented at the 14th International Conference of the International Building Performance Simulation Association, Hyderabad, India.

Kim, J.-H. (2016). The impact of occupant modelling on energy outcomes of building energy simulation (Doctoral dissertation). Georgia Institute of Technology.

Legge 90/13, Decreti Legge attuative di questa legge: (i) Decreto 26 giugno 2015 - DM requisiti minimi, (ii) Decreto 26 giugno2015 - Certificazione energetica, e (iii) Decreto 26 giugno2015 - Relazione tecnica; C.F.R. (2015).

Menezes, A. C., Cripps, A., Bouchlaghem, D., \& Buswell, R. (2012). Predicted vs. actual energy performance of non-domestic buildings: Using post-occupancy evaluation data to reduce the performance gap. Applied Energy, 97, 355-364. doi: 10.1016/j.apenergy.2011.11.075

Mora, D., Carpino, C., \& De Simone, M. (2017). Energy consumption of residential buildings and occupancy profiles. doi: 10.1007/s12053-017-9553-0

Motuziene, V., \& Vilutiene, T. (2013). Modelling the Effect of the Domestic Occupancy Profiles on Predicted Energy Demand of the Energy Efficient House. Procedia Engineering, 57, 798-807. doi: 10.1016/j.proeng.2013.04.101

Ouf, M. M., O’Brien, W., \& Gunay, H. B. (2018). Improving occupant-related features in building performance simulation tools. Building Simulation, 11(4), 803-817. doi: 10.1007/s12273-018-0443-y 
Santangelo, A., \& Tondelli, S. (2017). Occupant behaviour and building renovation of the social housing stock: Current and future challenges. Energy and Buildings, 145, 276-283. doi: 10.1016/j.enbuild.2017.04.019

Stevenson, F., \& Leaman, A. (2010). Evaluating housing performance in relation to human behaviour: new challenges. Building Research \& Information, 38(5), 437-441. doi: DOI: $10.1080 / 09613218.2010 .497282$

Sun, K., \& Hong, T. (2017). A simulation approach to estimate energy savings potential of occupant behavior measures. Energy and Buildings, 136, 43-62. doi: 10.1016/j.enbuild.2016.12.010

Th-BCE. (2012). Th-BCE.2012.Méthode de la réglementation thermique. Retrieved 18-052018, from http://ec.europa.eu/growth/toolsdatabases/tris/fr/index.cfm/search/?trisaction $=$ search.detail\&year $=2011 \&$ num $=159 \& \mathrm{fLa}$ $\underline{n g}=$ FR $\&$ dNum $=1$

UNE-EN 13829. Aislamiento térmico. Determinación de la estanqueidad al aire en edificios. Método de presurización por medio de ventilador. (2000).

Zhang, Y., Bai, X., Mills, F. P., \& Pezzey, J. C. V. (2018). Rethinking the role of occupant behavior in building energy performance: A review. Energy and Buildings, 172, 279294. doi: 10.1016/j.enbuild.2018.05.017 